\title{
A Finite Element Simulation for the Effect of Different Tool Profiling on Friction stir
}

\author{
welding for AA7075-T6 Alloy
}

\author{
Hari Dewangan $^{\# 1}$, Atul Chakrawarti², \\ ${ }^{1}$ MTech Scholar, ${ }^{2}$ Associate Professor
}

Department of Mechanical Engineering, Shri Shankaracharya Institute of Professional

Management and Technology, Raipur, Chhattisgarh 492015

\#Corresponding author, Email: haridewangan11@gmail.com

\begin{abstract}
Friction Stir Welding (FSW) is a new solid-state welding technique that finds application in various industries. It involves the joining of metals without any help of fusion or filler material. The joint between two metals can be formed through the combined action of frictional heating and mechanical deformation, which is developed due to a rotating tool. The friction act like a heat source that provides sufficient heat to stir the material. The material that flows around the tool undergoes an extreme level of plastic deformation. Rotation generates enough friction and the friction generates sufficient heat to soften the material. Friction Stir Welding (FSW) is used for welding aluminum alloys. However, interest is growing in utilizing the process in a wider range of applications that also employ non-aero engine metallic materials. Therefore, it is the objective ofthis paper is to provide a broad view of the capabilities of the FSW process for joining metals and also gives sense when welding is performed with different tool profile and rotational speed. This work will cover the basics of the process and the fundamental aspects of operating an FSW. This Includes a description of the different parameters that have been involved in this process and also their effect when parameters changed in form of tool geometry and rotational speed.
\end{abstract}

Key words: Friction stir welding, Tool pin profile, Aluminum alloy, Temperature field, Finite element analysis.

\section{Introduction}

Friction stir welding (FSW) is a recently developed solid-state welding by The Welding Institute (TWI) in 1991. [1] In this technique, joints between two metals can be formed through excessive friction which leads to a plasticized layer at the interface of the adjoining specimens. The material will deform due to a rotation of the tool and a sufficient amount of heat is generated by the friction forces acting between the welding tool and work piece, here the friction is generated because of adhesion between tool and workpiece, and plastic deformation because of tangential velocity in tool and workpiece. The tool shoulder rubs the work piece and generates sufficient heat, such that the material will become soft enough to stir it. FSW is mostly used for aluminum alloy as it eliminates the defect like blowholes, porosity, etc. which is developed in fusion welding technique. Since its invention back in 1991, TWI has continuously developed the FSW process for a wide range of applications and over the last 30 year there is some tool which is successful and some are patented. Aluminum is a key metal for industrial growth because of its high strength to weight ratio and its unique properties like strength, durability, conductivity, recyclability makes it a metal of choice for various industrial activities. [2] The growth of the aluminum industry can be attributed to its widespread application in major spheres of economic activities including infrastructure, construction, power, packaging, consumer durables, and automotive. In developed countries, aluminum has over 3,000 applications whereas, in developing countries, the usage is limited. Aluminum consumption is also reflected in the GDP of the country as a developed country consumes more aluminum as compared to a developing country. Aluminum can also produce less carbon footprint as it is required 5\% of energy to recycle. It is also called a critical metal for the European defense industry as it's useful 
for defence equipment. [3] Several researchers have already performed work on friction stir welding Jain et al. 2017, [4] have performed simulation on friction stir welding to study temperature distribution and strain distribution in aluminum (Grade AA2024) using the finite element method (DEFORM3Dsoftware). In this study, a threedimensional coupled thermo- mechanical method based on the Lagrangian implicit method is proposed. They defined Workpiece is as rigid viscoplastic material and von-mises yield criteria are used for stress and strain rate calculation. Sticking condition is defined between tool and work piece. Adaptive remeshing is used to tackle high mesh distortion. During the process total heat generation is equal to frictional heat generation and heat generation due to plastic deformation. The Temperature Distribution is best defined by the Fourier law of heat conduction and maximum temperature is found in the nugget zone and it is $546^{\circ} \mathrm{C}$ and the pin of the tool has a temperature of $146^{\circ} \mathrm{C}$. The Dimension of a workpiece is $80 \mathrm{~mm} \times 60$ $\mathrm{mm} \times 5 \mathrm{~mm}$. The Shoulder diameter of the tool is $24 \mathrm{~mm}$. The tapered cylindrical pin is used with a larger diameter of $7 \mathrm{~mm}$ with an included angle of $4^{\circ}$ and pin height of $4.6 \mathrm{~mm}$. K. Kumari et al. 2015, [5] designed and fabricated a new counter-rotating twin tool. They analyze the effect of a single tool using double pass (ST-DP) and twin tool on pure aluminum alloy with different welding speed and tool rotation in a Friction stir welding. They Found at $1800 \mathrm{rpm}$ and $63 \mathrm{~mm} / \mathrm{min}$ twin tool shows a higher hardness profile as compared to the single tool double pass. Jain et al. 2017, [6] have observed different performances on two different pins, i.e., smooth conical and threaded conical by developing a thermo mechanical model based on the Lagrangian method. They found that higher slip rate and vertical flow are observed in threaded conical pin and it's negligible for the smooth conical pin and axial and welding forces are lower in the threaded conical pin as compared to others. Sahu et al. 2016, [7] have done to see the effect of the Influence of plate position, tool offset, and tool rotational speed on mechanical properties and microstructures of dissimilar $\mathrm{Al} / \mathrm{Cu}$ friction stir welding joints. They found that a high-quality weld joint may be obtained by placing the copper plate on the advancing side of the tool rotation. Ujjwal etal. 2015,[8] have studied Defect identification in friction stir welding using discrete wavelet analysis to evaluate the transformation of force and torque signal. For this purpose, aluminum alloy AA1100is used whose specification was $200 \mathrm{~mm} \times 80 \mathrm{~mm} \times$ $2.5 \mathrm{~mm}$. The Defect can be analyzed in the form of a change in the force signal (Z-load). Frequency vs. time with varying resolution can be obtained in a discrete wavelet transform. High frequency has shown the detailed features whereas low frequency shows the original data. Chauhan et al. 2018, [9] have developed a coupled Eulerian and Lagrangian method to study the friction stir welding process. For this purpose, to analyze the defects, the volume of fluid principle is used in addition to this they have successfully calculated spindle torque and axial force developed during FSW. They simulate different heights of a pin and the optimum height is observed at $2.5 \mathrm{~mm}$ and the tilt angle is $2^{\circ}$. Ranjan et al. 2016, [10] have studied defect-free weld and mainly focused on surface defects during the FSW process. They have used digital image processing techniques to identify surface defects using image pyramid and image reconstruction algorithms. These defects are classified as voids, grooves, rough surface textures in a piece. Additionally, the area plot gives the density of all kinds of defects in a crosssection of the weld bead surface which can be used to analyze the percentage of good weld that occurred. Arora et al. 2009, [11] calculate the torque, power requirement during friction stir welding ofAA2524 aluminum alloy by solving the equation of conservation of mass, momentum, and energy. Several numerical models can be used for calculation of heat generation rate, heat transfer rate, and material flow and their validation corresponding to the experimental data and he concluded that torque requirement decreases as the tool rotation speed increases as it 
increases heat generation but the torque is not much affected as the welding speed increases. Bergmann et al. 2016, [12] focus on joining two aluminum plates, and the weld quality is compared with MIG welding based on tensile testing, hardness measurement, and microstructural analysis and they found FSW sample plate is a more uniform hardness profile and also porosity formation is eliminated. F. Lambiase et al. 2018,[13] investigated the variation of forces, torque, energy, and distribution of temperature during welding and the experiment is performed in $\mathrm{Al}-\mathrm{Si}-\mathrm{Mg}$ alloy with varying the tool rotation speed and welding speed. Temperature measurement can be calculated by IR camera. FSW is a defect-free process but welding of different dimension plates requires a special design of tool as the tool depends on a work piece and it is different for different dimensions of plate. In current work, the initial idea is to change the tool pin profile so excessive friction will increase around the tool and we focus on their future scopes. It is important to know the behavior of different profiles of a tool as it is changed by a change of profile of pin, forces, and torque are different for different tool. To reduce the force generation during the process and to come up with optimum process parameters it is important to know the characteristics of a different tool. The objective of the current work is to find the Temperature field, Welding force, and change in Torque for change in rotational speed for their future scope.

\section{Methodology \\ 2.1 Geometric modeling: -}

To successfully compute FSW it is important to make a geometric model of a Workpiece, tool, and backing plate. Dimension can be taken based on an experiment performed and different research papers. In this analysis, a geometric model is made with the help of ABAQUS as shown in fig. (2). Tool is defined as a rigid body because the strength of the tool is much higher than the workpiece and the workpiece is defined as a viscoplastic material because elastic deformation is negligible as compared to plastic deformation. For temperature calculation, we have to allow the thermal degree of freedom by simply adding the convective heat transfer coefficient. In this work, we are using three different tools of different profiles as shown in fig. (3), and the welding velocity is $80 \mathrm{~mm} / \mathrm{min}$. Plate size is $70 \mathrm{~mm} \times 140 \mathrm{~mm} \times 8$ $\mathrm{mm}$ and for cylindrical tool shoulder diameter (D) is $16 \mathrm{~mm}$, Pin diameter (d) is $6 \mathrm{~mm}$ and pin height $(\mathrm{h})$ is $7.8 \mathrm{~mm}$. For square pin Shoulder diameter (D) is $16 \mathrm{~mm}$ and side (a) are $6 \mathrm{~mm}$ and for tapered rectangle pin Shoulder (D) is $16 \mathrm{~mm}$ and the lower part size is $4 \mathrm{~mm}$ and the upper part size is $6 \mathrm{~mm}$.

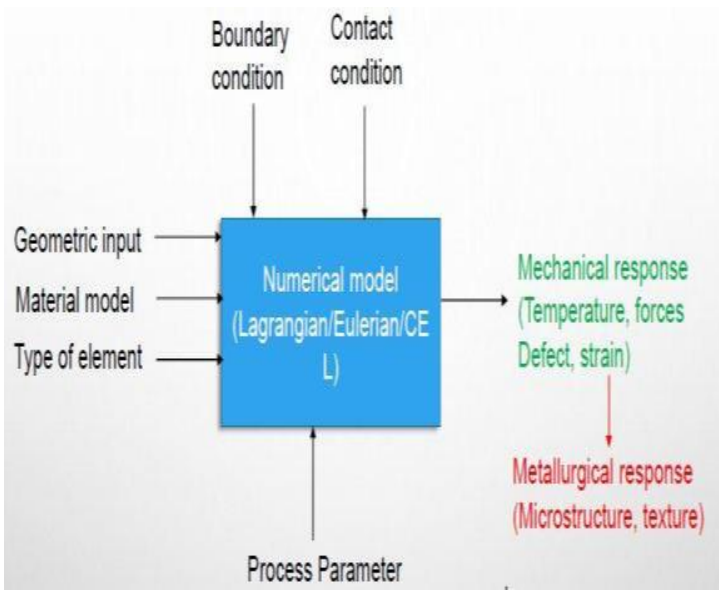

Fig.1 Modeling methodology in FSW

Several software that is commercially available for numerical and analytical modeling and software such as ABAQUS, ANSYS, DEFORM, etc. and their modeling methodology are shown in fig. (1). This is based on the Finite element method, Finite difference method, finite volume technique in the present work we are using ABAQUS 2017 software for modeling FSW, and the method used is the Finite element method.

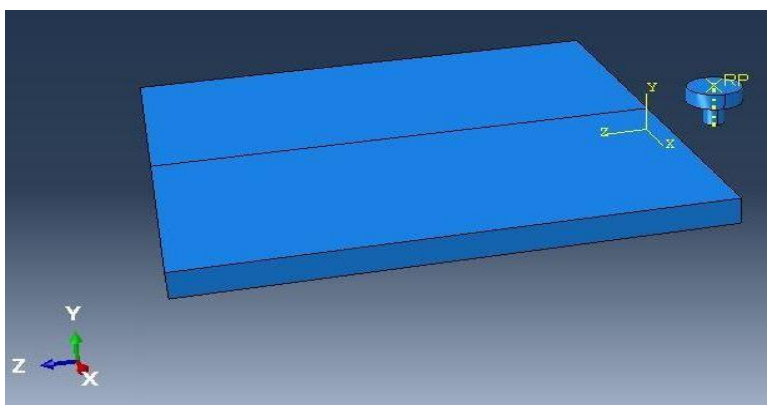

Fig.2 A schematic illustration of tool workpiece 


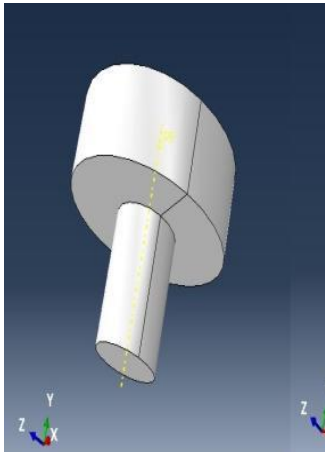

(a)

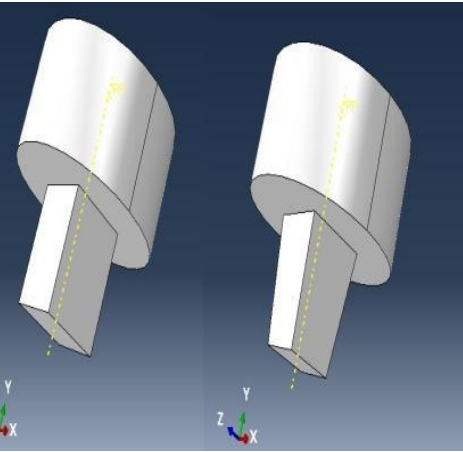

(b)

(c)
Fig.3 Schematic diagrams of tool pin-tip profiles: (a) Cylindrical(b) Square(c) Tapered rectangle.

\subsection{Material model:}

A variety of constitutive laws have been reported in the various literatures, and among them, Johnson-Cook model and SheppardWright model are the most commonly used.

2.3 Johnson cook material model: - The Johnson-Cook model (Johnson and cook 1983) is a multiplicative law. [15] It is a strain, temperature-dependent viscoplastic model fitted to a high strain rate process, as expressed in Eq. (1)

$$
\begin{array}{r}
\underline{\sigma}=\left[A+B \underline{\varepsilon}^{n}\right]\left[1+C \ln \ln \left(\frac{\underline{\underline{\varepsilon}}}{\dot{\varepsilon}_{0}}\right)\right][1- \\
\left.\left(\frac{T-T_{\text {room }}}{T_{\text {melt }}-T_{\text {room }}}\right) m\right]
\end{array}
$$

where $\underline{\sigma}, \varepsilon, \underline{\varepsilon}, \dot{\varepsilon}_{o}, T_{\text {room }}$ and $T_{\text {melt }}$ are flow stress, plastic strain, effective strain rate, reference strain rate $\left(1 \mathrm{~s}^{-1}\right)$, room temperature, and melting temperature, respectively. A (in $\mathrm{MPa}$ ) is the yield stress of the material at room temperature, $\mathrm{B}$ (in $\mathrm{MPa}$ ) and $\mathrm{n}$ depict the influence of strain hardening and are known as hardening modulus and work-hardening exponent, respectively. $\mathrm{C}$ and $\mathrm{m}$ are the strain rate hardening and thermal softening coefficient, respectively.

\subsection{Sheppard and Wright model:} According to this model, the effective viscosity $\mu_{e f f}$ is characterized as a function of effective flow stress $\sigma_{e}$ and effective strain rate $\underline{\varepsilon}$ as Eq. (2) [16]

$\mu_{\text {eff }}=\frac{\sigma_{e}}{3 \underline{\varepsilon}}$
Where the effective stress is a function of the strain rate and the temperature field and is expressed as Eq. (3)

$\sigma_{e}=\frac{1}{\alpha}\left(\frac{Z}{A}\right)^{\frac{1}{n}}(3)$

The temperature compensated strain rate parameter or Zener-Hollomon parameter (Z) associates the temperature and the strain rate in the form of Eq. (4) [17]

$z=\underline{\operatorname{sexp}}\left(\frac{Q}{R T}\right)$

where $\mathrm{Z}$ is the Zener-Hollomonparameter and $\mathrm{Q}(\mathrm{J} / \mathrm{mol})$ is the activation energy. $R=8.314$ $\mathrm{J} / \mathrm{mol} \cdot \mathrm{K}$ is the gas constant and $T$ is the absolute temperature.

In current work, we are usingAA7075 T-6 aluminum alloy whose composition weight percent (wt. \%) as written.

Table 1 AA7075 T-6 Metallurgy chemical composition of the work piece (wt. \%) [18]

\begin{tabular}{lccccccccc}
\hline Element & Al & $\mathrm{Mg}$ & $\mathrm{Cu}$ & $\mathrm{Cr}$ & $\mathrm{Fe}$ & $\mathrm{Si}$ & $\mathrm{Mn}$ & $\mathrm{Ti}$ & $\mathrm{Zn}$ \\
\hline (Wt. \%) & $87.1-$ & $2.1-2.9$ & $1.2-2$ & $0.18-28$ & $\mathrm{Max}$ & $\mathrm{Max}$ & $\mathrm{Max}$ & $\mathrm{Max}$ & $5.1-6.1$ \\
& 91.4 & & & & 0.5 & 0.4 & 0.3 & 0.2 & \\
& & & & & & & \\
\hline
\end{tabular}

Table 2 Properties of workpiece and tool material [18] [19]

\begin{tabular}{lll}
\hline Properties & AA7075 T-6 & Tool steel Hl3 \\
\hline Young modulus (N/mm $\left.{ }^{2}\right)$ & 71700 & 210000 \\
Thermal Conductivity (N/s $\left.{ }^{\circ} \mathrm{c}\right)$ & 130 & 24.5
\end{tabular}

\begin{tabular}{lcc} 
Heat capacity $\left(\mathrm{J} / \mathrm{g}^{\circ} \mathrm{c}\right)$ & 0.96 & 0.460 \\
$\begin{array}{l}\text { Coefficient of thermal expansion } \\
\left(\mu \mathrm{mm} / \mathrm{mm}^{\circ} \mathrm{c}\right)\end{array}$ & 25.2 & 11.7 \\
$\begin{array}{l}\text { Poisson's ratio } \\
\text { Density }\left(\mathrm{kg} / \mathrm{m}^{3}\right)\end{array}$ & 0.33 & 0.3 \\
\hline
\end{tabular}

2.5 Thermal Interaction: In FSW energy is always constant as the total heat generated is transfer to the tool with conduction and in the environment by the help of radiation and convection, also a part of the energy is accommodated at the workpiece which increases the temperature. A total flow of heat is as shown in Fig 4. [20] 


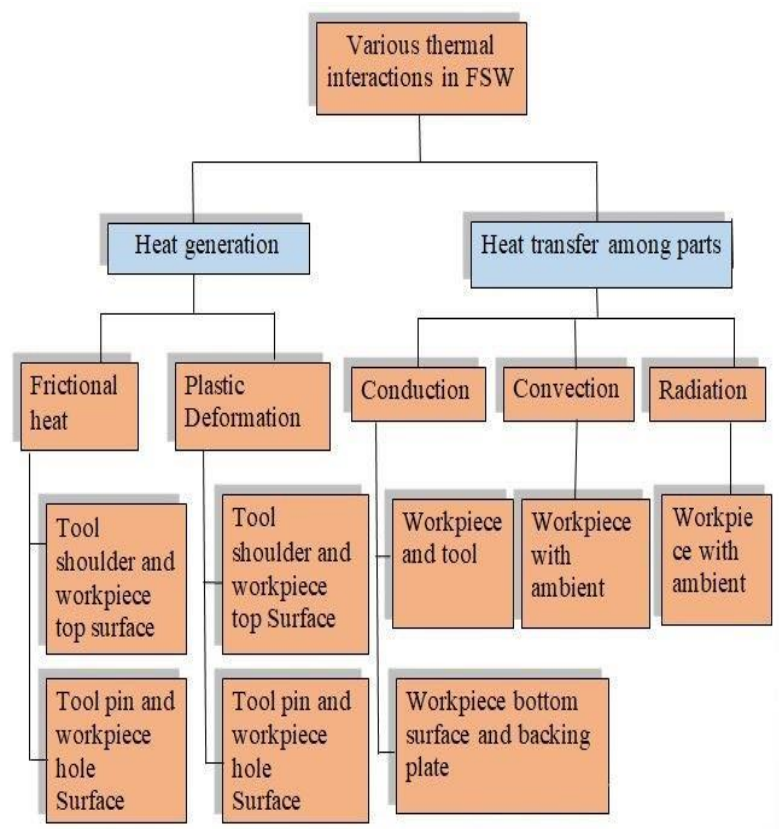

Fig. 4 various interactions of heat transfer in FSW

In FSW total heat generation is equal to friction and plastic deformation as expressed in Eq. (5) frictional heating is due to tangential frictional stress defined at interface and it is equivalent to the product of frictional stress and slip rate at the interface as expressed in Eq. (6) Heat generation due to plastic deformation depends on the amount of deformation and the rate of heat generation is a product of flow stress and strain rate, as expressed in Eq. (7) Distribution of the temperature within the workpiece and the tool is governed by the Fourier law of heat conduction, as expressed in Eq. (8). [9] The expressed Fourier law of heat conduction is for transient analysis, for steady-state analysis, the term on the right-hand side of the equation is equivalent to zero.

$$
\dot{q}=\dot{q}_{f}+\dot{q}_{p}
$$

$$
\dot{q}_{f}=\emptyset\left(\tau_{s} \times \dot{\gamma}\right)
$$

$\dot{q}_{f}=\eta(\sigma \times \dot{\varepsilon})$

(7)

$$
k \nabla^{2} T+\dot{q}=\rho c \frac{\partial T}{\partial t}
$$

Where $\rho, \mathrm{c}, \mathrm{t}, \dot{q}, \dot{q}_{f}, \phi, \dot{q}_{p}, \eta, \dot{\gamma}$, and $\mathrm{K}$ are the mass density, specific heat capacity, time, heat generation rate, frictional heat generation rate, frictional heat factor, heat generation rate due to plastic deformation, inelastic heat fraction, slip rate, and thermal conductivity of the material, respectively.

2.6 Contact Interaction: Tool and workpiece contact is based on shear frictional law which is defined as Eq. (9) with a constant shear factor of 0.4. Backing plate and workpiece contact is based on coulombs law of friction with a coefficient of friction of 0.2. [20] Various heat transfer phenomena have been defined to incorporate the heat loss to the tool, backing plate, and environment, as shown in Fig. (5). Convective heat transfer coefficients between the interacting pair of the toolworkpiece and workpiece-backing plate are defined such that total convective heat transfer between them is equivalent to the conduction in the experiment as expressed in Eq. (10) and Eq. (11), respectively. Eq. (12) incorporates the convective and radiation heat transfers between all surfaces of the workpiece (except bottom face) and environment. [20]

$\tau_{s}=m k$

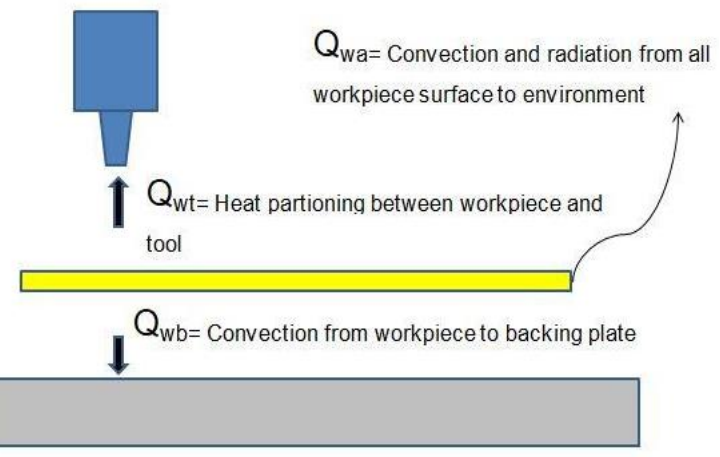

Fig. 5 Thermal interactions between different parts and environment

$Q_{w t}=K_{w t} \frac{\delta T}{\delta z}=h_{t}\left(T_{w}-T_{t}\right)(10)$

$Q_{w b}=K_{w b} \frac{\delta T}{\delta z}=h_{b}\left(T_{w}-T_{b}\right)$

$Q_{w a}=\sigma_{b} \varepsilon_{b}\left(T_{w}{ }^{4}-T_{w a}{ }^{4}\right)+h_{a}\left(T_{w}-T_{a}\right)$

where $Q_{w t}, K_{w t}, h_{t}, T_{w}, T_{t}, Q_{w b}, K_{w b}, h_{b}, T_{b}$, $Q_{w a}, \sigma_{b}, \varepsilon_{b}, h_{a}$, and $T_{a}$ are heat transfer from workpiece to the tool, conductance between the workpiece and tool, convective heat transfer coefficient between the workpiece and the tool, workpiece temperature, tool temperature, heat transfer between workpiece 
and backing plate, conductance between workpiece and backing plate, convective heat transfer between the workpiece and backing plate, backing plate temperature, total heat transfer between workpiece and environment, Stefan-Boltzmann constant, emissivity of the workpiece, convective heat transfer between the workpiece and environment, and environment temperature, respectively.

\section{Boundary conditions and assumptions} for the model: - Various boundary conditions are defined on the workpiece to replicate the clamping condition during an experiment. Side faces of the workpiece are constrained in $\mathrm{X}, \mathrm{Y}$, and $\mathrm{Z}$ directions to arrest any rigid motion. Rotational and translational movements are defined in the tool to consider different phases of FSW. The tool is rotated about the $\mathrm{Z}$ axis and travel velocity is defined in $\mathrm{Z}$ and $\mathrm{Y}$ axes for plunging and welding phase, respectively. Following are the assumptions made during modeling:

(a) Physical properties of the workpiece and tool are defined as independent of temperature, (b) uniform heat transfer between the bottom face of the workpiece and backing plate is considered, (c) shear factor is defined as a constant value, i.e., it is independent of temperature, and (d) tool and backing plate are defined as a rigid body. [9]

4.Governing equation:- The governing equation for this method consists of three equilibrium equations, as expressed in Eq. (13) in notation form, yield condition expressed in Eq. (14), and five strain rate ratios derived from the flow rule Eq. (15).[20] Equilibrium condition:

$\frac{\partial \sigma_{i j}}{\partial \sigma_{i j}}=0 \quad(\mathrm{i}, \mathrm{j}=1,2,3)$

Yield criterion:

$f\left(\sigma_{i j}\right)=C, \underline{\sigma}=\sqrt{\frac{3}{2} \sigma_{i j}{ }^{\prime} \sigma_{i j}}$

Constitutive equation:

$\dot{\varepsilon}_{i j}=\frac{3}{2} \underline{\underline{\varepsilon}} \underline{\underline{\sigma}} \sigma_{i j}^{\prime}$ with $\underline{\varepsilon} \cdot=\sqrt{32\left\{\dot{\varepsilon}_{i j} \dot{\varepsilon}_{i j}\right\}}$

(15)

Compatibility condition: $\dot{\varepsilon}_{i j}=\frac{1}{2}\left(\frac{\partial u_{i}}{\partial x_{j}}+\frac{\partial u_{j}}{\partial x_{i}}\right)$

\section{Results and Discussion: -Overall FSW} process is simple but the material flow behavior is difficult and it depends on the tool pin profile, as the pin profile changed material flow is changed which is a reason for variation in process parameter and which is discussed below.

5.1 Temperature: - FSW process simulation is successfully done for three different tool pin profile and we are observed that maximum temperature is found in tapered rectangle tool because resultant tangential velocity found in tapered rectangle tool in two plane horizontal and vertical plane and due to this vertical tangential velocity, it allows the material to mixed in thickness direction also which generated more friction and heat.

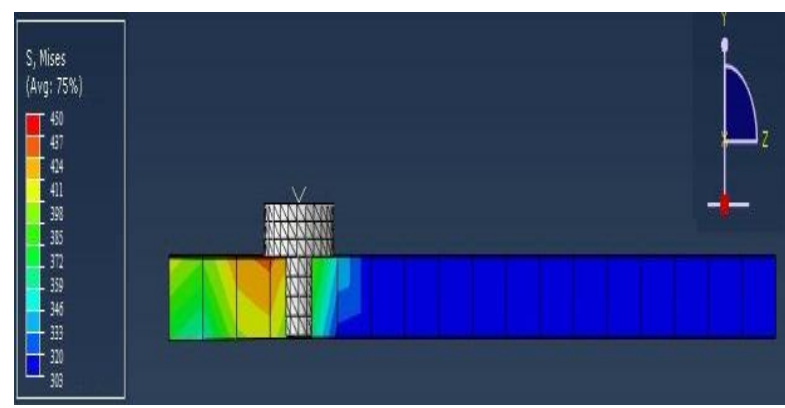

Fig. (6) Temperature profile of the cylindrical pin profile tool

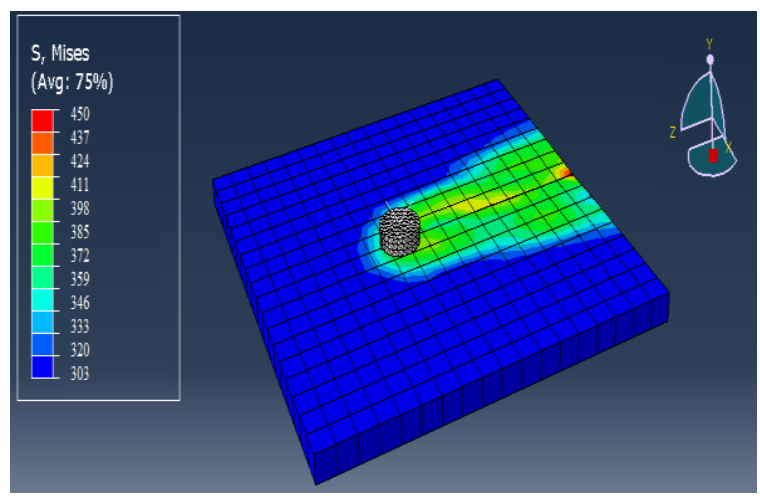

Fig. 7 Temperature contour of the cylindrical pin profile tool

The temperature produce in tapered rectangle tool is $3.5 \%$ more than a square tool and $6.73 \%$ more than a cylindrical tool for 1200 rpm and temperature distribution found in V shape because near the tool, on a surface of 
the workpiece present a heat source in form of friction and also there is a difference in convective heat transfer coefficient between the top of workpiece and environment, and bottom of workpiece and environment which are also a reason for $\mathrm{V}$-shaped temperature profile. Fig. (6) and Fig. (7) Show the temperature distribution for a cylindrical tool with $800 \mathrm{RPM}$ and $80 \mathrm{~mm} / \mathrm{min}$. As an increase in rotational speed temperature increases because the relative velocity between tool and workpiece also increases. The variation of temperature with increase in rotational speed as shown in Fig. (8) Where (a) is the temperature variation for cylindrical tool, (b) is the temperature variation for square tool, and (c) is the temperature variation in tapered rectangular tool. The maximum temperature is found at $490^{\circ} \mathrm{C}$ for cylindrical tool, $505^{\circ} \mathrm{C}$ for square tool, and $523^{\circ} \mathrm{C}$ for tapered rectangle tool at $1200 \mathrm{rpm}$ which is found at the center of the weld as tool probe and shoulder generates maximum heat. The temperature profile attains a $\mathrm{v}$ shape as the shoulder diameter is greater than the pin diameter which leads to higher heat generation on the upper surface of the workpiece.

5.2 Welding force: -Welding force is a force required to weld the workpiece along the weld line and also the resistance of translational movement of the tool and depends on the cross-section of pin profile. Welding force requirement is more in the square tool because it's having a square cross- section whose volume is more as compare to other two tools and the volume of material deformation is dependent on the volume of pin profile. Welding force requirement in square tool is $15 \%$ more as compared to tapered rectangle tool and $19 \%$ more than a cylindrical tool. Fig. 9 Shows the variation of welding force in three different pin profile and its decreases as rotational speed increases as the material flow is higher in high rotational speed and the stress required to yield the material is lower.

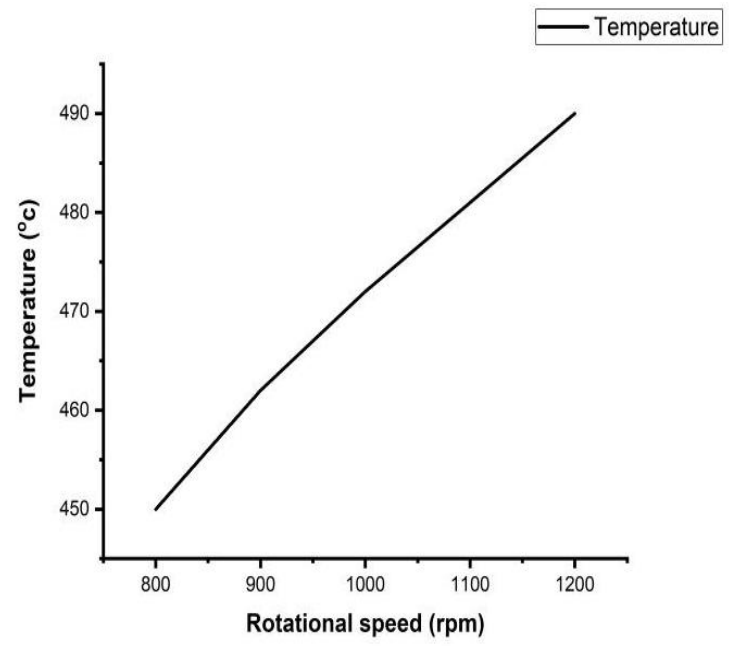

(a)

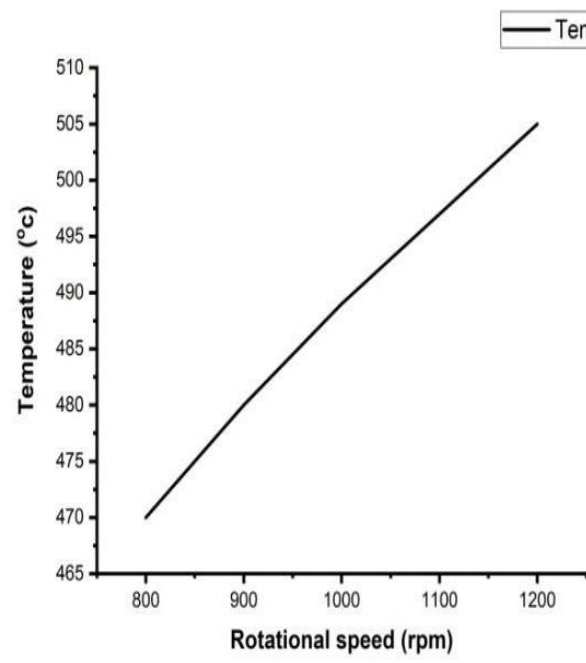

(b)

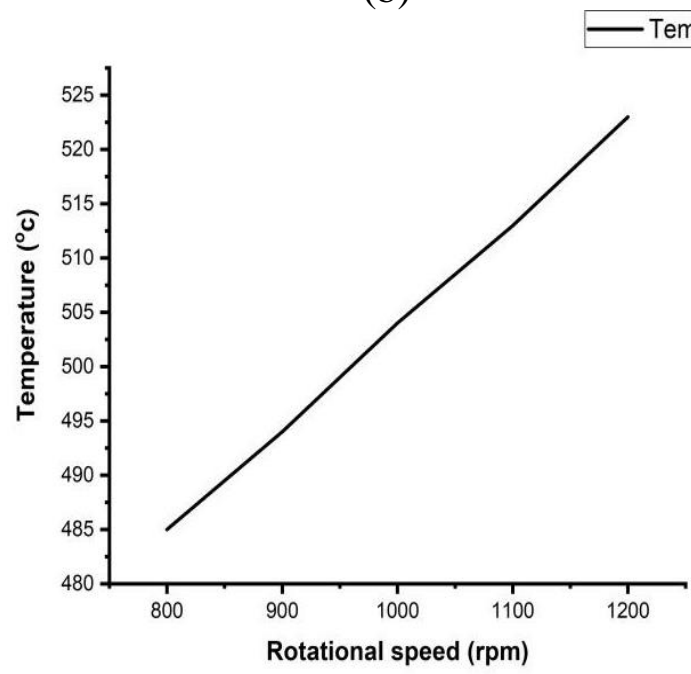

(c)

Fig. 8 Temperature variation for tool pin tip profile (a) cylindrical (b) square (c) tapered rectangle 


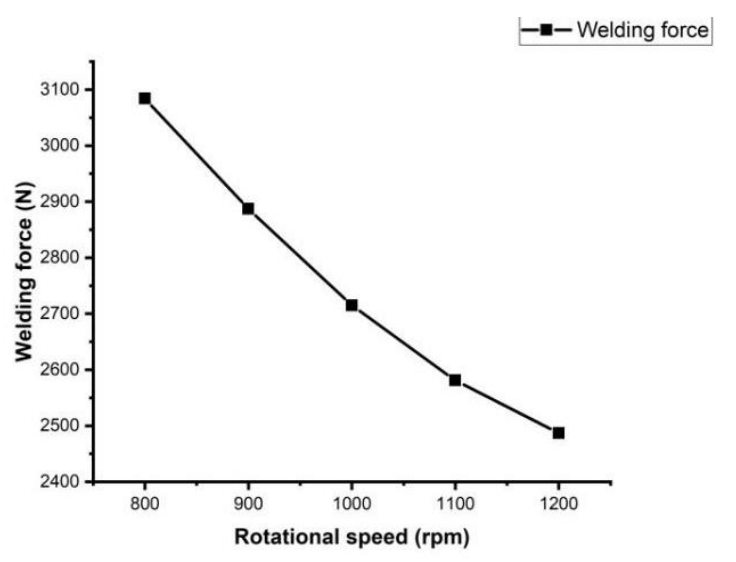

(a)

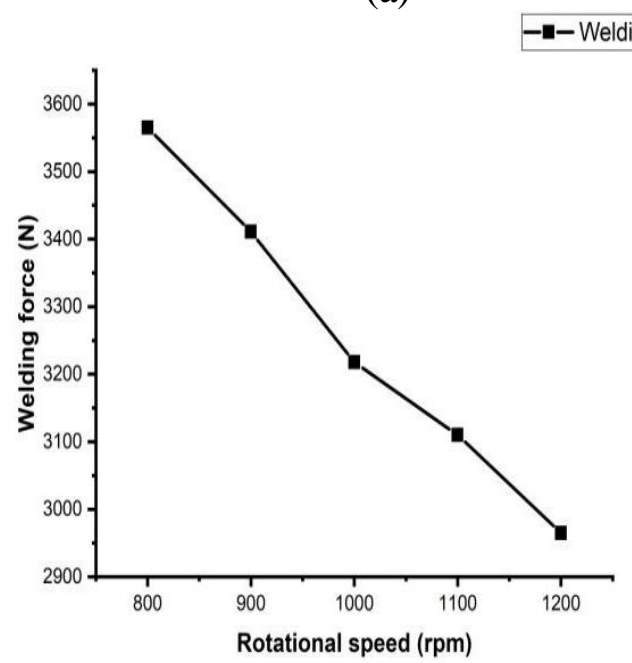

(b)

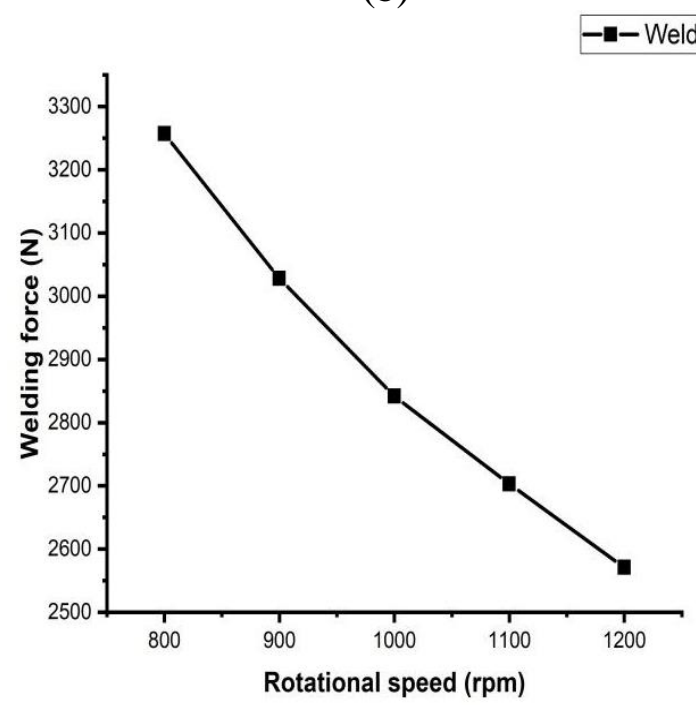

(c)

Fig. 9 Welding force variation for tool pin tip profile (a) cylindrical (b) square (c) tapered rectangle

5.3 Torque: Torque is an important factor as it indicates the power consumption during the process and also important for the selection of motors for FSW machines. Spindle torque is reduced as an increase in rotational speed because at higher rpm flow of material is easier as it's developed more heat and high temperature.

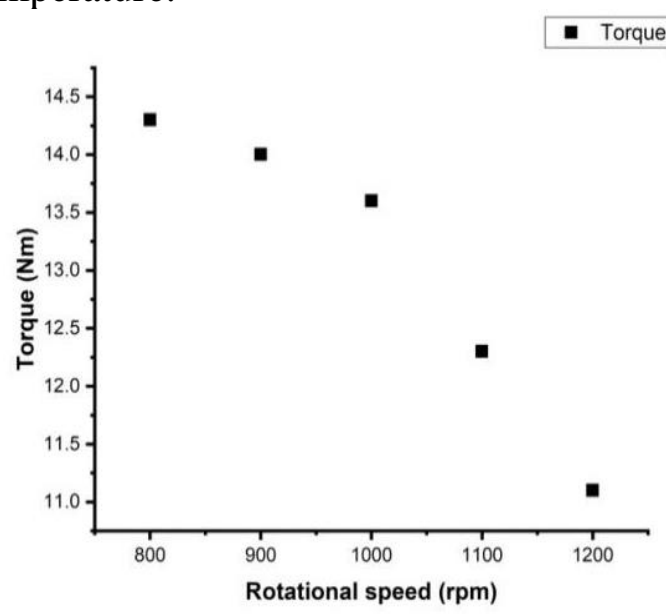

(a)

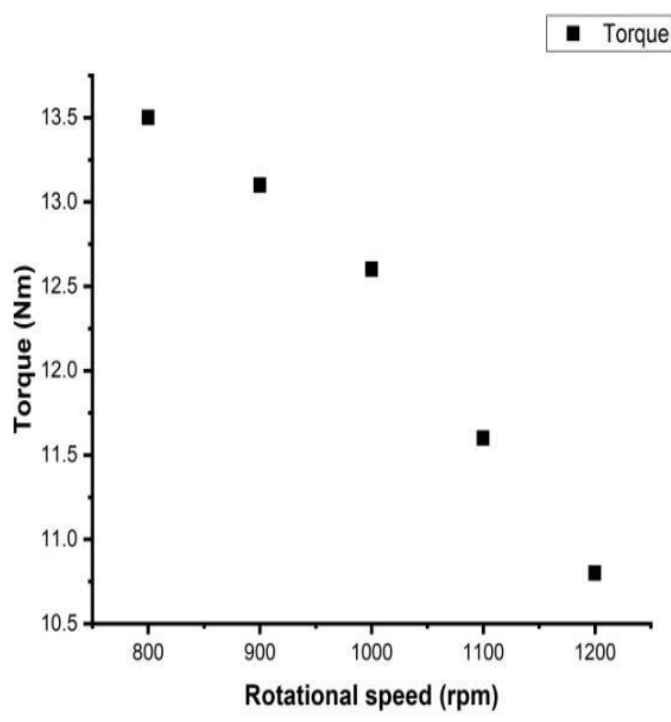

(b)

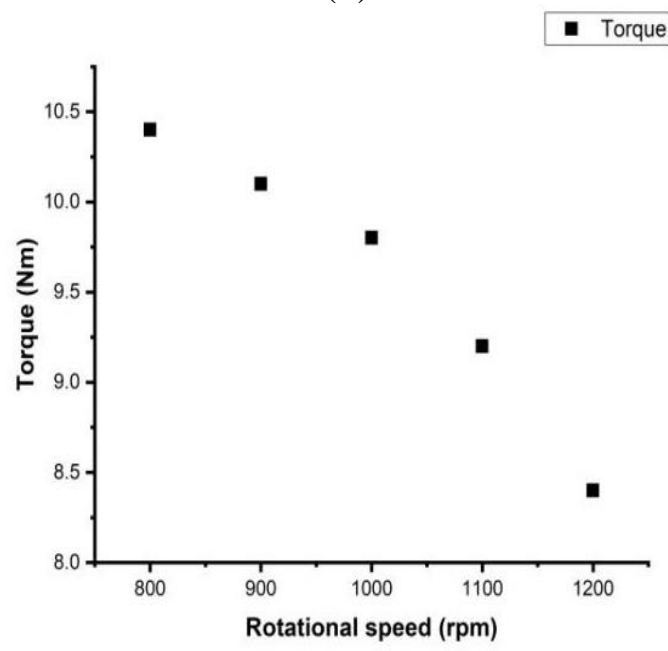

(c)

Fig. 10 Torque variation for tool pin tip profile (a) cylindrical (b) square (c) tapered rectangle 


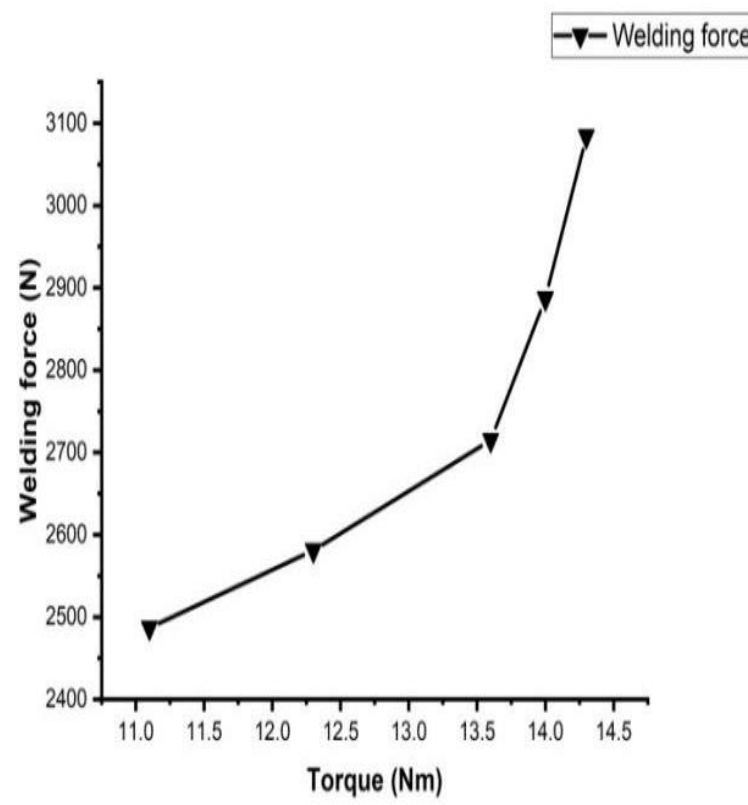

(a)

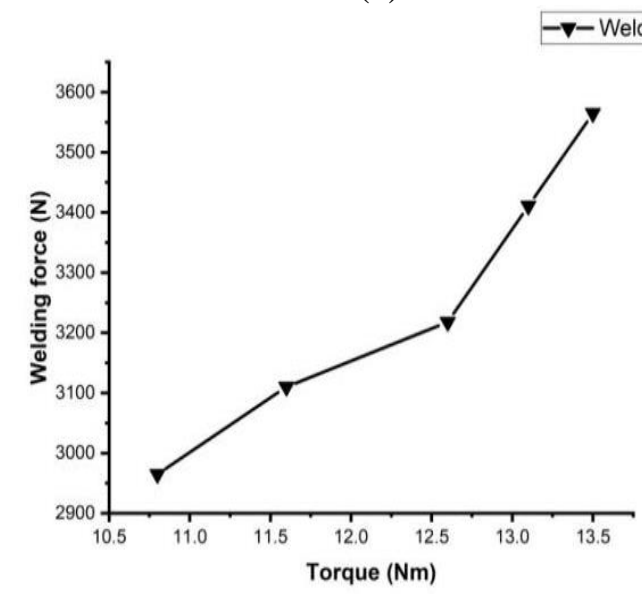

(b)

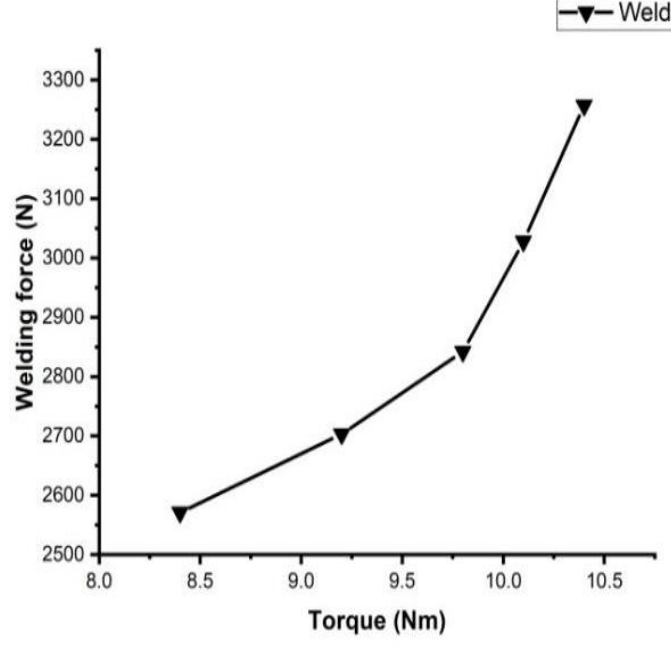

(c)

Fig. 11 Welding force and torque variation for tool pin tip profile (a) cylindrical (b) square (c) tapered rectangle

Tapered rectangle tool generates more heat and temperature means torque requirement is less, and in the cylindrical tool, as it developed less temperature more torque required and it is $32 \%$ more than tapered rectangle tool and $2.8 \%$ more than a square tool. Fig. (10) Shows variation in spindle torque and as seen tapered rectangle tool required less torque as compared to the other two tool pin profile.

5.4 Welding force and torque: A key parameter of FSW is weld force and torque. The proper and consistent application of force improves the mating of the materials and reduces the interface resistance, and ensuring that any oxide barriers between the workpieces are broken through. Fig. (11) shows welding force and torque variation for three different tool pin tip profile and it shows for an increase in force the torque requirement also increases as more power are consumed in the process.

\section{Conclusion}

In this study, three different pin-tip profiles were designed for friction stir welding of 8 mm-thick AA7075 T-6 aluminum alloy plates. The effects of pin-tip profile on temperature distribution, welding force, and torque were investigated. The following conclusions are derived.

1. The temperature increases as rotational speed increases as the shoulder directly in contact with the top surface of the workpiece which acts as a heat source caused by excessive friction. Maximum Temperature is found at the top surface and as a tool profile changes it supports the temperature increment. The maximum temperature is higher in tapered tool and it is 0.82 times the melting temperature of AA7075 T-6 aluminum alloy.

2.The welding force requirement decreases as rotational speed increases due to excessive heat metal in a viscous plastic zone as the rotational speed increases relative velocity between tool and workpiece also increases which cause easy to move material in this stage and as shown welding force is maximum for a square tool at $1200 \mathrm{rpm}$ 
because it displaces maximum volume which creates resistance for translational movement. 3 . Torque is the energy required to move the material and it's directly related to heat generation as more heat softens the material and hence torque requirement is less for tapered rectangle tool more temperature generated means a torque requirement is less as compared to the other two tool profile.

\section{Conflict of Interest}

The authors declare no conflict of interest.

\section{References}

[1] Thomas, W.M., Nicholas, E.D., Needham, J.C., Murch, M.G., Templesmith, P. and Dawes, C.J. (1991) International Patent Application No. PCT/GB92/02203 and GB Patent Application No. 9125978.8.

[2] Jain, R., Kumari, K., Kesharwani, R., Kumar, S., Pal, S., Singh, S., Panda, S. and Samantaray, A., 2015. Friction Stir Welding: Scope and Recent Development. Materials Forming, Machining and Tribology, pp.179. 229.

[3] V.K Saraswat, Aniruddha Ghosh, need for an Aluminum Policy in India, NitiAayog, published on 2017.

[4] Jain, R., Pal, S. and Singh, S., 2016. Finite Element Simulation of Temperature and Strain Distribution during Friction Stir Welding of AA2024 Aluminum Alloy. Journal of The Institution of Engineers (India): Series C, 98(1), pp.37-43.

[5] Kumari, K., Pal, S. and Singh, S., 2015. Friction stir welding by using counterrotating twin tool. Journal of Materials Processing Technology, 215, pp.132-141.

[6] Jain, R., Pal, S. and Singh, S., 2017. Finite element simulation of pin shape influence on material flow, forces in friction stir welding. The International Journal of Advanced Manufacturing Technology, 94(5-8), pp.1781-1797.

[7] Sahu, P., Pal, S., Pal, S. and Jain, R., 2016. Influence of plate position, tool offset and tool rotational speed on mechanical properties and microstructures of dissimilar $\mathrm{Al} / \mathrm{Cu}$ friction stir welding joints. Journal of Materials Processing Technology, 235, pp.55-67.
[8] Kumar, U., Yadav, I., Kumari, S., Kumari, K., Ranjan, N., Kesharwani, R., Jain, R., Kumar, S., Pal, S., Chakravarty, D. and Pal, S., 2015. Defect identification in friction stir welding using discrete wavelet analysis. Advances in Engineering Software, 85, pp.43-50.

[9] Chauhan, P., Jain, R., Pal, S. and Singh, S., 2018. Modeling of defects in friction stir welding using coupled Eulerian and Lagrangian method. Journal of Manufacturing Processes, 34, pp.158166.[10] Ranjan, R., Khan, A., Parikh, C., Jain, R., Mahto, R., Pal, S., Pal, S. and Chakravarty, D., 2016. Classification and identification of surface defects in friction stir welding: An image processing approach. Journal of Manufacturing Processes, 22, pp.237-253.

[11] Arora A, Nandan R, Reynolds AP, DebRoy T (2009) Torque, power requirement and stir zone geometry in friction stir welding through modeling and experiments. Scripta Mater 60 (1):13-16.

[12] Bergmann, J., Grätzel, M., Schürer, R., Regensburg, A. and Weigl, M., 2016. Advances and Potentials in Friction Stir Welding of Aluminum Alloys. Key Engineering Materials, 710, pp.137-142.

[13]Lambiase, F., Paoletti, A., \& Di Ilio, A. (2018). Forces and temperature variation during friction stir welding of aluminum alloy AA6082-T6. The International Journal of Advanced Manufacturing Technology, 99(14), 337-346. https://doi.org/10.1007/s00170018-2524-6 [14] Kuykendall, K., Nelson, T., Sorensen, C., 2013. On the selection of constitutive laws used in modeling friction stir welding. Int. J. Mach. Tools Manuf. 74, 74-85.

http://dx.doi.org/10.1016/j.ijmachtools.2013. 07.004 .

[15] Johnson GR, Cook WH. A constitutive model and data for metals subjected to large strains, high strain rates and high temperatures. Proc 7th IntSympBallist 1983; 547:541-7.

http://dx.doi.org/10.1038/nrm3209.

[16] Kuykendall, K., 2011. An Evaluation of Constitutive Laws and their Ability to Predict 
Flow Stress over Large Variations in Temperature, Strain, and Strain Rate Characteristic of Friction Stir Welding. Brigham Young University.

[17] Sheppard, T., Wright, D.S., 1979. Determination of flow stress: part 1 constitutive equation for aluminum alloys at elevated temperatures. Met. Technol. (June), 215-223.

[18] Metals Handbook, Vol.2 - Properties and Selection: Nonferrous Alloys and SpecialPurpose Materials, ASM International 10th Ed. 1990.

[19] Jain, R., Pal, S. K., \& Singh, S. B. (2016). A study on the variation of forces and temperature in a friction stir welding process: A finite element approach. Journal of Manufacturing Processes, 23, 278-286. https://doi.org/10.1016/j.jmapro.2016.04.008 [20] Jain, R., Pal, S. K., \& Singh, S. B. (2017). Numerical modeling methodologies for friction stir welding process. Computational Methods and Production Engineering, 125169. https://doi.org/10.1016/b978-0-85709481-0.00005-7. 